\title{
RESEARCH ON BALLISTIC RESISTANCE OF DCPD LAMINATE UNDER PISTOL AMMUNITION FIRE
}

\author{
D. Pyka ${ }^{*}$, K. Jamroziak ${ }^{* *}$, G. Ziolkowski ${ }^{* * *}$, J. Pach ${ }^{\dagger}$, M. Bocian ${ }^{\ddagger}$
}

\begin{abstract}
This paper describes an investigation of the ballistic resistance of DCPD matrix composite reinforced with aramid fabric. The resistance was tested using 0.44 Magnum ammunition at a mean initial speed of $380 \mathrm{~m} / \mathrm{s}$. Detailed analysis of the projectile impact energy dissipation process was conducted using computed tomography. In that way it was possible to register the local area connected to the energy dissipation of the penetrating projectile and its deformation. The results of computational analysis were used to conduct detailed research with the use of numerical methods in ABAQUS. Based on numerical and experimental research, conclusions were formulated about the shielding properties of material systems with the new matrix type.
\end{abstract}

Keywords: ballistic shields, impact loads, numerical analysis, SEM, tomography

\section{Introduction}

Today, composite materials have gained great popularity in ballistic shield design, especially those which are reinforced with high-strength fibers, such as aramid, Ultra High Molecular Weight Polyethylene (UHMWPE), glass, carbon and PBO fibers (Bilisik, 2010). The parameters defining the ballistic properties of composites are the mechanical properties of reinforcement, geometrical features and the matrix. In current literature, most papers describe research on composite materials based on a polymeric and epoxy matrix (Rojek et al., 2013; Bandaru et al., 2016 and Mayer, 2017). The matrix can dissipate up to $30 \%$ of the impact Energy while cracking. The Energy level defining matrix delamination is much lower than the Energy level leading to fiber damage. Based on previous investigations, it was noted that it is possible to enhance the threshold Energy for the matrix as well as design a fiber behavior so that it would allow the Energy to be dissipated on a larger area compared to a typical matrix.

This paper presents an excerpt of the research on a Dicyclopentadiene (DCPD) based matrix application. Using modern research tools and methods, such as computed tomography 3D representation, Scanning Electron Microscope (SEM) and numerical simulations, the Energy dissipation of 0.44 Magnum Semi Jacketed Hollow Point (SJHP) projectile type with a specified mass of $15.6 \mathrm{~g}$ and a velocity of $410 \mathrm{~m} / \mathrm{s} \pm$ $10 \mathrm{~m} / \mathrm{s}$ was analyzed. Investigations are conducted in order to increase the ballistic limit of material systems designed for ballistic shields against energetically enhanced pistol projectiles. The aim is ballistic

MSc., Eng. Dariusz Pyka: Wroclaw University of Science and Technology, Faculty of Mechanical Engineering, Department of Mechanics, Materials Science and Engineering, Smoluchowskiego 25, Wroclaw 50-370, Poland, dariusz.pyka@pwr.edu.pl

** Assoc. Prof. Krzysztof Jamroziak, DSc., Eng.: Wroclaw University of Science and Technology, Faculty of Mechanical Engineering, Department of Mechanics, Materials Science and Engineering, Smoluchowskiego 25, Wroclaw 50-370, Poland, krzysztof.jamroziak@pwr.edu.pl

*** Assis. Prof. Grzegorz Ziolkowski, DSc., Eng.: Wroclaw University of Science and Technology, Faculty of Mechanical Engineering, Department of Laser Technology, Automation and Production Organization, Lukasiewicza 5, Wroclaw 50-370, Poland, grzegorz.ziolkowski@pwr.edu.pl

$+\quad$ Assis. Prof. Joanna Pach, DSc., Eng.: Wroclaw University of Science and Technology, Faculty of Mechanical Engineering, Department of Foundry, Polymers and Automation, Lukasiewicza 5, 50-370 Wroclaw, Poland, joanna.pach@pwr.edu.pl

‡ Assis.Prof. Miroslaw Bocian, DSc., Eng.: Wroclaw University of Science and Technology, Faculty of Mechanical Engineering, Department of Mechanics, Materials Science and Engineering, Smoluchowskiego 25, Wroclaw 50-370, Poland, miroslaw.bocian@pwr.edu.pl 
system optimization in terms of mass and volume, enhancing its shielding properties and reduction of Back Face Deformation (BFD).

\section{Methods}

To prepare a DCPD matrix laminate sample, Twaron ${ }^{\circledR}$ aramid fabric of $280 \mathrm{~g} / \mathrm{m}^{2}$ basic weight and plain weave structure was used as reinforcement. The fabric thickness of $0.4 \mathrm{~mm}$ has a fiber density of approx. $1.45 \mathrm{~g} / \mathrm{cm}^{3}$, and a fiber diameter of $12 \mu \mathrm{m}$. For laminate production, 12 layers of fabric were used, where the sample had a thickness of $4.4 \mathrm{~mm}$ and a weight of $224 \mathrm{~g}$. Modified DCPD was used as the matrix resin, which is a by-product secreted from processing crude oil. The polymerization process was carried out in the presence of a second-generation Grubbs catalyst. The paper matrix applied in this is characterized by improved parameters of static tensile and bending strength, high relative elongation at rupture and high compressive strength in comparison to other types of resins. After super saturation with DCPD the material was subjected to pressure at room temperature $\left(21^{\circ} \mathrm{C}\right)$ at a pressure of approx. $1.5 \mathrm{MPa}$ and was left for 12 hours. The resultant laminate was cut into $100 \times 100 \mathrm{~mm}$ pieces (the size was dependent on the coupling on the test stand) in order to perform a ballistic track according to the U.S. Department of Justice NIJ-Standard (NIJ, 2008). The macroscopic results of the impact are presented in the Fig. 1.

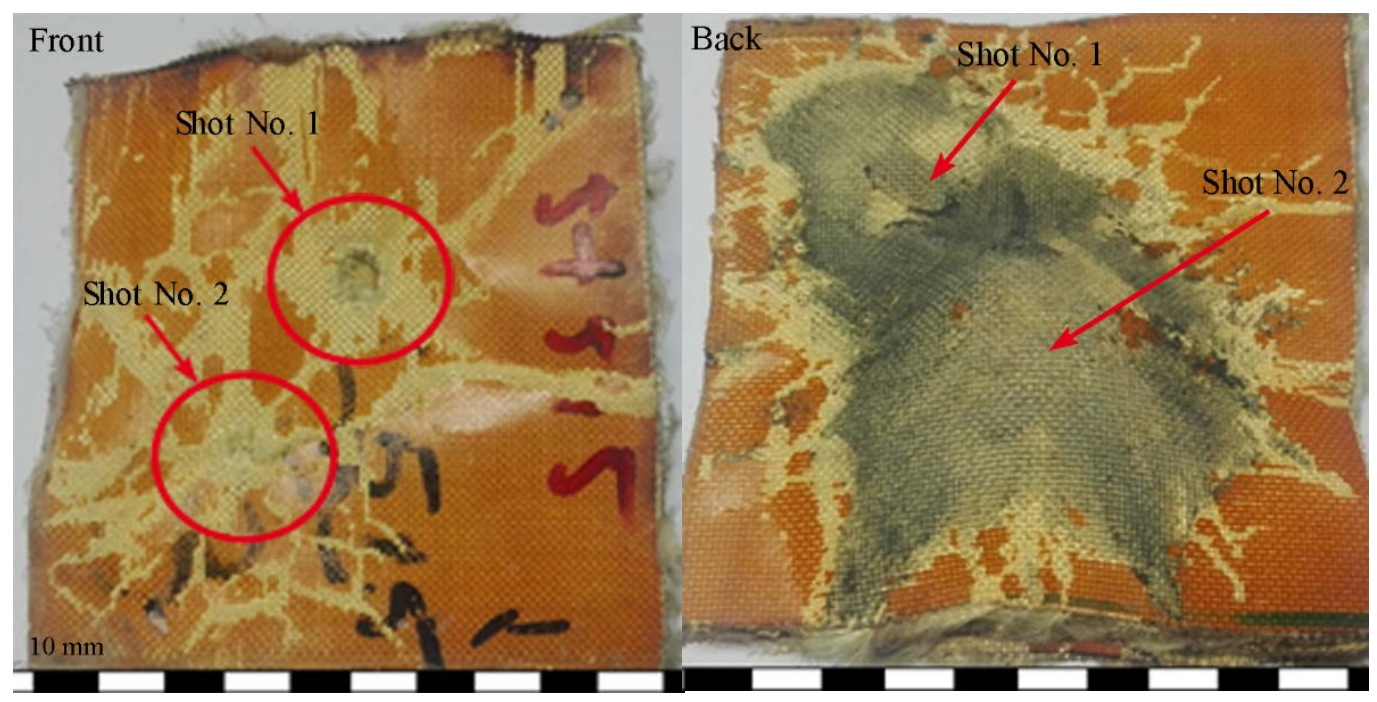

Fig. 1: Sample after shooting.

\section{SEM and tomography analyses}

A scanning electron microscope, an in-depth analysis of the matrix and the strengthening of the material as a result of the impact were carried out. SEM images show that the laminate is properly saturated with the resin, as the resin is present between individual strands of fiber (Fig. 2).

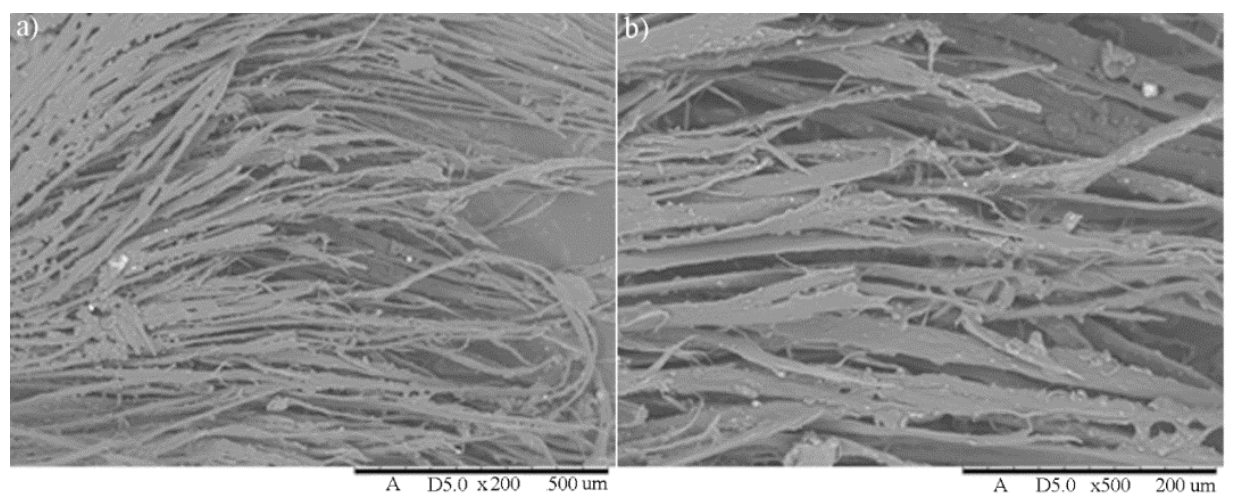

Fig. 2: SEM images after projectile: a) inlet, b) outlet. 
Next the material system was scanned using technical computed tomography (METROTOM 1500 Carl Zeiss, Oberkochen, Germany) with the following parameters: tube voltage: $220 \mathrm{kV}$, current intensity: $500 \mu \mathrm{A}$, cupreous filter: 3mm, projection integration time: $4 \mathrm{~s}$, voxel: $115 \mu \mathrm{m}$. Effect correction Beam Hardening was applied in order to decrease the level of measurement distortion agents. Visualization was conducted using VG Studio MAX 2.0 (Volume Graphics GmbH, Heidelberg, Germany). Selected results are shown in Fig. 3.
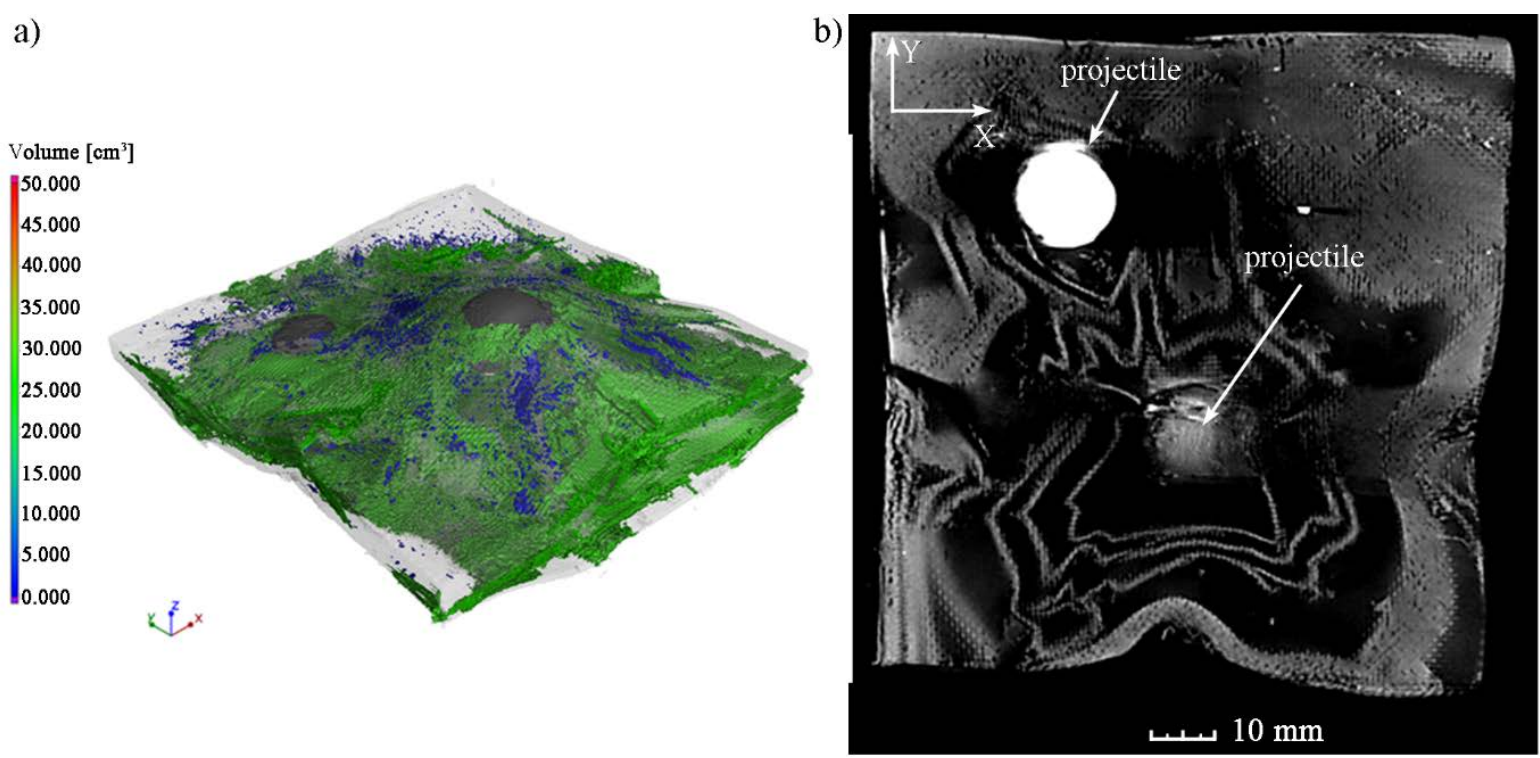

Fig. 3: Tomographic images: a) crack distribution, b) cross-section image.

\section{Numerical analysis}

Ballistic simulations performed in the ABAQUS program were narrowed in order to simplify the numerical model of the projectile, namely, including in the analysis only the core of the projectile and the translation speed, that is, omission of the projectile rotation (Baranowski et al., 2015; Barnat et al., 2011 and Mazurkiewicz et al., 2015). The kinetic energy of the projectile was calculated based on an average speed of the projectile of $382.2 \mathrm{~m} / \mathrm{s}$ and its mass, $15.6 \mathrm{~g}$, thus the initial kinetic energy is as $1.13 \mathrm{~kJ}$. The projectile shape was based on Sellier \& Bellot ammunition, which was used in experimental research. The numerical model of the composite was based on aramid fabric discretization including adhesion to DCPD resin (Bocian et al., 2017). The material data used for the simulation are summarized in Table 1.

Tab. 1: Characteristics of the projectile material properties, aramid material and DCPD.

\begin{tabular}{lcccccccc}
\hline \multirow{2}{*}{ Specification } & $E$ & $v$ & $\rho$ & $A$ & $B$ & $n$ & $S I G Y$ & $F S$ \\
\cline { 2 - 9 } & {$[\mathrm{GPa}]$} & {$[-]$} & {$\left[\mathrm{kg} / \mathrm{m}^{3}\right]$} & {$[\mathrm{MPa}]$} & {$[\mathrm{MPa}]$} & {$[-]$} & {$\left[\mathrm{N} / \mathrm{m}^{2}\right]$} & {$[-]$} \\
\hline Core lead & 16 & 0.42 & 11300 & 24 & 40 & 1 & - & - \\
\hline $\begin{array}{l}\text { Jacket } \\
\text { (brass M90) }\end{array}$ & 115 & 0.31 & 8940 & 206 & 505 & 0.42 & - & - \\
\hline Twaron & & 0.3 & 1450 & - & - & - & $3.6 \mathrm{E}+9$ & 0.04 \\
\hline DCPD & 3.1 & 0.2 & 98 & 15 & 18 & - & - & - \\
\hline
\end{tabular}

Where: $E$ - Young's modulus, $v$ - Poisson's ratio, $A$ - yield at zero plastic strain, $B$ - hardening constant, $n$ - hardening exponent, SIGY - Yield strength, FS - Effective plastic strain, failure criterion.

The obtained results were compared to those obtained from computed tomography. It allowed the results to be verified and assessed. Based on the results presented in Fig. 4. it was noted that the level of both results correspondence is high. That conforms to properly assumed material properties, material homogenization and shield damage model in both the elastic and plastic range. 


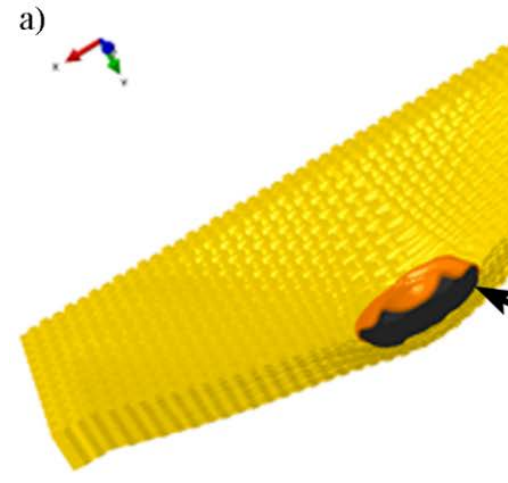

a)

Fig. 4: Investigated composite damage visualization: a) finite element method, b) tomographic transparent image shot No. 1.

\section{Conclusions}

Based on the observed results of experimental research, where the mean impact speed differed from the norm, we concluded that the new matrix type is characterized by better adhesion and fiber saturation. This was reflected in obtaining a positive result, that is stopping the 0.44 Magnum projectile, whereas under the same conditions but for different matrix, polyvinyl chloride (PVC), the result was negative. As presented in Fig. 2, that type of matrix causes a different type of fiber damage. It is visible that the reinforcement and the matrix absorb the impact energy correctly. This is confirmed on tomography images (Fig. 3). Local damage is distributed over a larger area. Registered BFD parameters and numerical simulation results confirm the research target. Describing ballistic impact energy dissipation and conducting experimental research helped to estimate the direction of further investigation on optimization of new matrix composites. Future research will be connected with achieving the projectile speed stated in the norm, detailed analysis of the processes taking place in the matrix, as well as strengthening using acoustic emission.

\section{Acknowledgement}

Calculations have been carried out in Wroclaw Centre for Networking and Supercomputing (http://www.wcss.pl), grant No. 452.

\section{References}

Bandaru, A.K., Chavan, V.V., Ahmad, S., Alagirusamy, R. and Bhatnagar, N. (2016) Ballistic impact response of Kevlar ${ }^{\circledR}$ reinforced thermoplastic composite armors. International Journal of Impact Engineering, 89, pp.1-13.

Baranowski, P., Malachowski, J., Niezgoda, T. and Mazurkewicz, L. (2015) Dynamic behaviour of various fibre systems during impact interaction-numerical approach. Fibres \& Textiles in Eastern Europe, 13, 6(114), pp. 7281.

Barnat, W., Dziewulski, P., Niezgoda, T. and Panowicz, R. (2011) Application of composites to impact energy absorption, Computational Materials Science 50, 4, pp. 1233-1237.

Bilisik, K. (2010) Experimental determination of ballistic performance of newly developed multiaxis noninterlaced/non-Z E-glass/polyester and 3D woven carbon/epoxy composites with soft backing aramid fabric structures. Textile Research Journal, 81. 5, pp. 520-537.

Bocian, M., Pach, J., Jamroziak, K., Kosobudzki, M., Polak, M., Pyka, D., Kurzawa, A. and Kurowski, J. (2017) Experimental and numerical analysis of aramid fiber laminates with DCPD resin matrix subjected to impact tests. MATEC Web of Conferences, https://doi.org/10.1051/matecconf/201711204013

Mazurkiewicz, L., Malachowski, J. and Baranowski, P. (2015) Optimization of protective panel for critical supporting elements. Composite Structures 134, pp. 493-505.

Mayer, P., Pyka, D., Jamroziak, K., Pach, J. and Bocian, M. (2017) Experimental and numerical studies on ballistic laminates on the polyethylene and polypropylene matrix. Journal of Mechanics, https://doi.org/10.1017/jmech.2017.103

NIJ Standard-0101.06, Ballistic Resistance of Body Armor. U.S. Department of Justice, July 2008.

Rojek, M., Szymiczek ,M., Stabik, J., Mezyk, A., Jamroziak, K., Krzystala, E. and Kurowski J. (2013) Composite materials with the polymeric matrix applied to ballistic shields. Archives of Materials Science and Engineering, 63, 1, pp. 26-35. 